\section{Phacoemulsification with intravitreal triamcinolone in patients with cataract and coexisting diabetic macular oedema: a 6-month prospective pilot study}

DSC Lam, CKM Chan, S Mohamed, TYY Lai,
VYW Lee, WW Lai, DSP Fan and W-M Chan

DSC Lam, CKM Chan, S Mohamed, TYY Lai,
VYW Lee, WW Lai, DSP Fan and W-M Chan

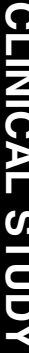

Department of

Ophthalmology \& Visual Sciences

The Chinese University of Hong Kong

Hong Kong Eye Hospital

Hong Kong

a safe option for managing diabetics with cataract and CSMO. However, large-scaled randomised controlled trials are necessary for delineating the relative contributions of cataract removal and CMT reduction to visual improvement. Moreover, the transient effect on CMT may warrant further studies to determine optimal timing and dosage of further ivTA injections.

Eye (2005) 19, 885-890. doi:10.1038/sj.eye.6701686; published online 24 September 2004

Keywords: intravitreal triamcinolone; diabetic macular oedema; cataract; phacoemulsification

\section{Introduction}

Diabetic macular oedema is the main cause of visual impairment in diabetic patients. ${ }^{1}$ Cataract is another well-recognised ocular complication of diabetes and it has been estimated that up to $20 \%$ of all cataract surgeries are performed on diabetics. ${ }^{2}$ The issue of whether cataract surgery causes acceleration of diabetic retinopathy or maculopathy has been controversial. Squirrell et $a l^{3}$ recently showed that uncomplicated phacoemulsification did not cause progression of diabetic retinopathy postoperatively and that any progression observed probably represents the natural history of the disease. ${ }^{3}$ However, the presence of maculopathy at the time of surgery
Correspondence: DSC Lam Department of

Ophthalmology \& Visual Sciences

The Chinese University of Hong Kong University Eye Center 3/F., Hong Kong Eye Hospital

147K Argyle Street Kowloon, Hong Kong Tel: + 85227623157

Fax: +852 21941369

E-mail: dennislam@ cuhk.edu.hk

Received: 29 March 2004 Accepted: 18 June 2004 Published online: 24 September 2004

Financial and proprietary interest: Nil

Financial Support: Supported in part by Action for Vision Foundation, Hong Kong

The data in this paper were presented in part as an oral presentation at the fourth Congress of the AsianOceanic Glaucoma Society, 1-4 October 2003 Hong Kong 
has been suggested to be a risk factor for poorer visual outcome and therefore some authors have recommended that cataract surgery be performed earlier in diabetics to avoid this risk. ${ }^{4-6}$ If clinically significant macular oedema (CSMO) is identified before surgery, the Royal College of Ophthalmologists' guidelines for cataract surgery in diabetics state that it should be treated at least 12 weeks prior to surgery. ${ }^{7}$ However, it is not uncommon to see patients with significant cataract that impedes the treatment or even diagnosis of CSMO. It has also been recommended that pre-existing CSMO identified after surgery should be treated promptly but the results are usually poor. ${ }^{7}$ There is also a subgroup of patients with diabetic CSMO refractory to conventional macular laser photocoagulation. The issue of whether and when it is safe to perform cataract surgery in these patients remains uncertain.

The development of macular oedema is thought to involve breakdown of the inner blood-retina barrier with release of endogenous permeability factors by an ischaemic retina. ${ }^{8}$ Triamcinolone acetonide, an intermediate acting corticosteroid suspension with a depot effect lasting up to 41 days in animal studies, ${ }^{9}$ can reduce breakdown of the blood-retinal barrier, ${ }^{10}$ inhibit the production of prostaglandins and downregulate production of vascular endothelial growth factor (VEGF). Injection of intravitreal triamcinolone (ivTA) with dosage ranging from 2 to $25 \mathrm{mg}$ has been used to treat macular oedema arising from a variety of causes. ${ }^{11-14}$

The early treatment in diabetic retinopathy study (ETDRS) demonstrated the benefits of laser photocoagulation in reducing progressive visual loss and persistent oedema in patients with CSMO.${ }^{15}$ However, only $14.5 \%$ of patients gained visual improvement 3 years after initial grid laser treatment. ${ }^{16}$ Martidis et $a l^{17}$ showed that $4 \mathrm{mg}$ ivTA in patients with CSMO refractory to laser photocoagulation resulted in a mean improvement of 2.4 lines in Snellen visual acuity with anatomical improvement in macular oedema demonstrated by OCT. In contrast, vision in most patients treated with laser photocoagulation tends to stabilise rather than improve. ivTA injection may therefore be an attractive alternative for treating CSMO especially in patients with significant cataract that impedes accurate application of laser. However, ivTA injection is not without potential risks including transient rise in intraocular pressure (IOP), cataract progression, vitreous haemorrhage, retinal detachment, as well as endophthalmitis. ${ }^{18-23}$

This study aims to report the safety and efficacy of phacoemulsification with ivTA injection in diabetic patients with dual pathologies of cataract and CSMO.

\section{Patients and methods}

Patients with CSMO with concurrent cataract were prospectively recruited between January and August 2003.
Evaluation and management of all patients took place at Hong Kong Eye Hospital. All patients were diagnosed with CSMO according to the ETDRS criteria as well as concurrent significant cataract. Informed consent was obtained from all patients, and the study protocol was reviewed and approved by the Clinical Research Ethics Committee of the Chinese University of Hong Kong. The study was carried out according to the tenets of the Declaration of Helsinki.

Inclusion criteria of the study include: (1) patients with type I or type II diabetes mellitus, (2) significant cataract (grade N02NC2C1P0.1 or above according to the Lens Opacity Classification System III), and (3) diffuse central macular oedema of at least $250 \mu \mathrm{m}$ as demonstrated by OCT (StratusOCT ${ }^{\mathrm{TM}}$, Carl Zeiss, Dublin, USA). Exclusion criteria of the study were (1) previous ocular trauma and ocular surgery; (2) patients who received laser photocoagulation less than 3 months before enrolment, (3) presence of significant media opacity other than cataract, for example, vitreous haemorrhage, (4) proliferative diabetic retinopathy and other ocular conditions requiring immediate treatment. Patients with a history of raised IOP were not excluded from the study, but the IOP had to be controlled at less than $21 \mathrm{mmHg}$ for at least 3 months prior to the enrolment.

Standard cataract extraction by phacoemulsification and intracapsular intraocular lens implantation was performed under topical anaesthesia, using 2\% lidocaine hydrochloride gel (Xylocaine, AstraZeneca) in an operation theatre setting. All surgeries were carried out by two of the authors (DSCL or VYWL). At the end of the cataract surgery, $4 \mathrm{mg}$ of triamcinolone acetonide (Kenacort A, Bristol-Myers Squibb, Amagni, Italy) in $0.1 \mathrm{ml}$ was injected at a site $3.5 \mathrm{~mm}$ posterior to the inferotemporal limbus using a $27 \mathrm{G}$ needle.

Postoperatively, $1 \%$ prednisolone acetate eye drops (Pred Forte, Allergan, Westport, Ireland) with 0.5\% levofloxacin (Cravit, Santen, Osaka, Japan) or 0.5\% chloramphenicol (Martindale Pharmaceuticals, Romford, England) eye drops were applied four times daily for 1 week, then weaning down weekly over a 3-week period.

At baseline examination, best corrected visual acuity (BCVA), OCT central macular thickness, and IOP were documented. The response to treatment was monitored functionally by BCVA assessment using ETDRS logMAR chart and anatomically by OCT macular thickness at weeks 1-4 and months 2-6 after surgery. Patients were also examined for potential corticosteroid-induced and surgery-related complications. At each postoperative visit, IOP was measured using a noncontact tonometer (Xpert NCT Plus, Reichert Ophthalmic Instruments), taken as a mean of three readings. If the IOP was greater than $20 \mathrm{mmHg}$, it was verified with a Goldmann applanation tonometer. Topical antiglaucomatous 
treatment was initiated if the IOP rose above $21 \mathrm{mmHg}$ and the treatment was tapered or stopped when the ivTA crystals were no longer visualised in the vitreous space and if the IOP was under control.

Statistical analysis was performed using SPSS v11.0. Nonparametric analysis using the Wilcoxon sign ranked test was carried out for serial comparison of BCVA and OCT central macular thickness. A difference was considered statistically significant if $P \leqslant 0.05$.

\section{Results}

\section{Patient demographics at baseline}

A total of 19 eyes in 15 consecutive patients underwent phacoemulsification with injection of $4 \mathrm{mg}$ ivTA. Four patients underwent phacoemulsification with ivTA in both eyes. The mean age of the patients was 71.4 years (range 63-86 years). Patient demographics, including previous treatment for CSMO are summarised in Table 1. All eyes had diabetic retinopathy at baseline ranging from mild to moderate severity as defined by ETDRS criteria. The mean duration of CSMO prior to surgery was 18.5 months and seven (36.8\%) eyes received previous grid laser photocoagulation. The mean preoperative BCVA was $1.00 \pm 0.40 \log \mathrm{MAR}$ units, which is an approximate Snellen equivalent (ASE) of 6/60. The mean baseline central macular thickness was $449 \pm 119 \mu \mathrm{m}$ and the mean baseline IOP was $13.9 \pm 3.0 \mathrm{mmHg}$. None of the patients developed any complications intraoperatively. One patient died from an unrelated cause 3 months after surgery and one eye developed subretinal macular haemorrhage secondary to age-related macular degeneration. These two patients were excluded from analysis. The remaining 17 eyes all completed 6 months of follow-up.

\section{Visual outcome}

The mean BCVA improved to a maximum of $0.74 \pm 0.37 \log$ MAR units (ASE 6/33), which was achieved at 4 months postinjection. The final mean BCVA at 6 months was $0.76 \pm 0.30 \log$ Mar units (ASE 6/35). The improvement of BCVA was statistically significant at both 4 months $(P=0.004)$ and 6 months $(P=0.015)$ postoperatively. The mean improvement in Snellen visual acuity was 2.4 lines at 6 months. Of the 17 eyes, $10(58.8 \%)$ had visual improvement of 2 or more lines in BCVA at 6 months after surgery, with the remaining seven $(41.2 \%)$ eyes having a final BCVA of within 2 lines

Table 1 Demographics of 19 patients who underwent phacoemulsification with injection of ivTA for cataract and diabetic macular oedema

\begin{tabular}{|c|c|c|c|c|c|c|c|c|c|c|c|}
\hline \multirow{2}{*}{$\begin{array}{l}\text { Patient } \\
\text { number }\end{array}$} & \multirow{2}{*}{$\begin{array}{l}\text { Age } \\
\text { (years) }\end{array}$} & \multirow[t]{2}{*}{$\operatorname{Sex}$} & \multirow{2}{*}{$\begin{array}{c}\text { Duration of } \\
\text { CSMO }^{a} \text { (months) }\end{array}$} & \multicolumn{4}{|c|}{ Cataract grading at baseline ${ }^{b}$} & \multicolumn{3}{|c|}{ Number of previous laser treatments } & \multirow[t]{2}{*}{ PHT } \\
\hline & & & & NO & NC & $C$ & $P$ & Focal & Grid & Focal E grid & \\
\hline $1^{\mathrm{c}}$ & 81 & $\mathrm{~F}$ & 11 & 6.0 & 6.0 & 3.0 & 1.0 & 1 & 0 & 0 & $\mathrm{~N}$ \\
\hline 2 & 74 & M & $\geqslant 8$ & 4.0 & 4.0 & 3.0 & 3.0 & 0 & 3 & 0 & $\mathrm{Y}$ \\
\hline 3 & 69 & M & 3 & 2.0 & 2.0 & 3.0 & 1.0 & 0 & 0 & 0 & $\mathrm{~N}$ \\
\hline $4 a$ & 74 & $\mathrm{~F}$ & 36 & 2.0 & 2.0 & 1.0 & 2.0 & 2 & 1 & 0 & $\mathrm{Y}$ \\
\hline $4 b$ & 74 & $\mathrm{~F}$ & 26 & 3.0 & 3.0 & 3.0 & 2.0 & 0 & 2 & 0 & $\mathrm{Y}$ \\
\hline $5 a$ & 72 & $\mathrm{~F}$ & $\geqslant 56$ & 3.0 & 3.0 & 3.0 & 2.0 & 3 & 0 & 0 & $\mathrm{~N}$ \\
\hline $5 b$ & 72 & $\mathrm{~F}$ & 24 & 3.0 & 3.0 & 2.0 & 1.0 & 0 & 0 & 0 & $\mathrm{Y}$ \\
\hline $6 a$ & 74 & $\mathrm{M}$ & 56 & 5.0 & 5.0 & 3.0 & 4.0 & 1 & 0 & 1 & $\mathrm{~N}$ \\
\hline $6 b^{c}$ & 74 & $\mathrm{M}$ & 41 & 4.0 & 4.0 & 3.0 & 4.0 & 1 & 0 & 1 & $\mathrm{~N}$ \\
\hline 7 & 70 & M & $\geqslant 7$ & 3.0 & 3.0 & 1.0 & 3.0 & 1 & 0 & 0 & $\mathrm{Y}$ \\
\hline $8 a$ & 66 & $\mathrm{~F}$ & 3 & 4.0 & 4.0 & 3.0 & 0.1 & 0 & 0 & 0 & $\mathrm{~N}$ \\
\hline $8 b$ & 66 & $\mathrm{~F}$ & 22 & 2.0 & 2.0 & 2.0 & 0.1 & 1 & 0 & 1 & $\mathrm{~N}$ \\
\hline 9 & 63 & $\mathrm{~F}$ & 27 & 2.0 & 2.0 & 2.0 & 3.0 & 1 & 0 & 0 & $\mathrm{~N}$ \\
\hline 10 & 65 & $\mathrm{M}$ & $\geqslant 2$ & 4.0 & 4.0 & 3.0 & 1.0 & 0 & 0 & 0 & $\mathrm{~N}$ \\
\hline 11 & 77 & $\mathrm{~F}$ & $\geqslant 14$ & 4.0 & 4.0 & 2.0 & 2.0 & 0 & 0 & 1 & $\mathrm{~N}$ \\
\hline 12 & 86 & $\mathrm{~F}$ & 1 & 4.0 & 4.0 & 3.0 & 1.0 & 0 & 0 & 0 & $\mathrm{~N}$ \\
\hline 13 & 64 & M & $\geqslant 1$ & 4.0 & 4.0 & 1.0 & 1.0 & 0 & 0 & 0 & $\mathrm{~N}$ \\
\hline 14 & 68 & M & 5 & 2.0 & 2.0 & 1.0 & 0.1 & 0 & 0 & 0 & $\mathrm{~N}$ \\
\hline 15 & 68 & $\mathrm{M}$ & 7 & 2.0 & 2.0 & 2.0 & 1.0 & 0 & 0 & 0 & $\mathrm{Y}$ \\
\hline
\end{tabular}

$\mathrm{CSMO}=$ clinically significant macular oedema; $\mathrm{PHT}=$ posterior hyaloid thickening

a Duration of documented CSMO prior to injection of ivTA, some patients had CSMO on their first consultation, in which case the duration was expressed as at least $(\geqslant) X$ months.

${ }^{\mathrm{b}}$ Cataract grading was performed using Lens Opacity Classification System III where NO= nuclear opalescence, NC $=$ nuclear colour, $\mathrm{C}=$ cortical, $\mathrm{P}=$ posterior subcapsular zone.

'Patients excluded from data analysis. Patient 1 died from an unrelated cause and $6 \mathrm{~b}$ developed exudative age-related macular degeneration. 


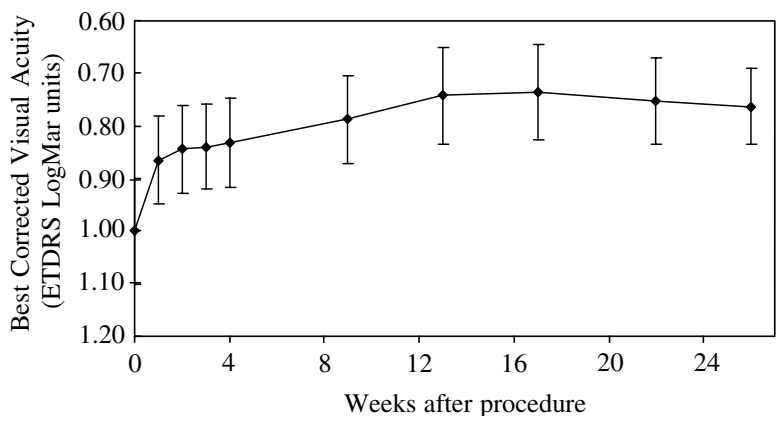

Figure 1 Changes in mean best-corrected visual acuity (BCVA) after combined cataract extraction and $4 \mathrm{mg}$ ivTA injection, over a 6-month period. The error bars show the standard errors of the mean.

compared with the preoperative BCVA. The changes in BCVA over 6 months are summarised in Figure 1.

\section{Central macular thickness}

The mean CMT was $339 \mu \mathrm{m}$ at 1 month (24.5\% reduction), $331 \mu \mathrm{m}$ at 3 months (26.3\% reduction), and $408 \mu \mathrm{m}$ at 6 months of follow up (9.1\% reduction). The minimum mean CMT after surgery occurred 2 months postoperatively with a mean thickness of $321 \pm 148 \mu \mathrm{m}$ (28.5\% reduction). The mean maximum improvement in CMT was $179 \pm 88 \mu \mathrm{m}$ (range, $56-336 \mu \mathrm{m}$ ). The mean reduction in CMT after surgery was statistically significant at all postoperative time intervals until 6 months postoperatively. By 6 months, the mean central macular thickness was $409 \pm 142 \mu \mathrm{m}$, and the difference was no longer statistically significant as compared to the baseline $(P=0.23)$. All eyes except one had a gradual recurrence of macular oedema during the 6-month follow-up period. The changes in CMT are summarised in Figure 2.

\section{Side effect profile}

Four $(23.5 \%)$ of 17 eyes developed an increase in IOP of over $21 \mathrm{mmHg}$ during the follow-up period. The IOP had normalised by 6 months without need for antiglaucomatous treatment in three eyes. One patient with no prior history of raised IOP developed elevated IOP at 5 months postoperatively that could be controlled with two topical medications (Timolol, Apraclonidine). There was one eye that developed subretinal macular haemorrhage secondary to exudative age-related macular degeneration as mentioned above. No other adverse events including injection-related complications, and in particular endophthalmitis, were encountered in this study.

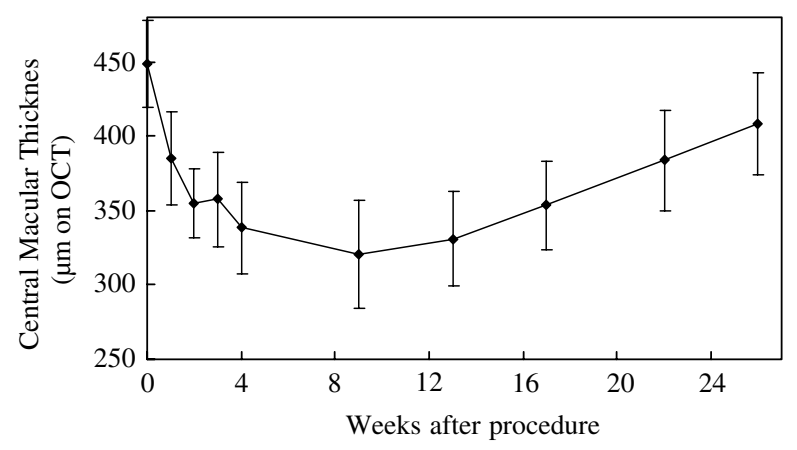

Figure 2 Changes in mean CMT after combined cataract extraction and $4 \mathrm{mg}$ ivTA injection, over a 6-month period. The error bars show the standard errors of the mean.

\section{Discussion}

In this pilot study, we studied an alternative approach to the common problem of how to manage diabetic patients with cataract and coexisting CSMO. In patients with CSMO detected preoperatively, treatment with macular laser photocoagulation is recommended at least 12 weeks prior to surgery. ${ }^{7}$ However, this may be difficult in patients with significant cataract. Diabetic CSMO refractory to conventional laser treatment methods is also not an uncommon problem. Our study may be of particular relevance to such patients. Preliminary results from our study indicate that cataract extraction with injection of ivTA may be performed safely in these patients without risk of significant complications such as persistent IOP rise and endophthalmitis. Moreover, these patients had statistically significant improvement in BCVA postoperatively, which was maintained after 6 months of follow-up.

Much of the existing data in the literature suggest that diabetic patients with CSMO at the time of cataract surgery have poorer visual outcomes. ${ }^{4-7}$ In the study by Dowler et $a l,{ }^{4}$ all patients with CSMO at the time of surgery had persistence of macular oedema at the 1-year follow-up with poorer visual outcome. In our study, seven eyes $(36.8 \%)$ had persistent CSMO at baseline in spite of previous grid macular laser treatments. Of the 17 eyes, $10(58.8 \%)$ had improvement by 2 or more lines at 6 months after cataract surgery with injection of ivTA, with the remaining seven eyes having a BCVA within two lines compared with baseline. Anatomically, the central macular oedema of patients who had phacoemulsification together with ivTA injection showed reduction to a minimum CMT achieved at 2 months and which was sustained at 3 months. However, by 6 months of follow-up, the reduction as compared to baseline was no longer statistically significant in most eyes. 
Recurrence of macular oedema following ivTA injection is not uncommon. In total, $37.5 \%$ of eyes were found to have recurrence of macular oedema 6 months after ivTA injection for refractory diabetic macular oedema in the study by Martidis et al. ${ }^{17}$ The development of a component of pseudophakic cystoid macular oedema (Irvine-Gass syndrome) is a possible confounding factor in our study and may be more common in diabetic patients undergoing cataract extraction as compared to the incidence in nondiabetics. ${ }^{24}$ One limitation of our study is the lack of fundus fluorescein angiography to differentiate between the recurrence of true diabetic macular oedema or Irvine-Gass syndrome after cataract surgery. However, the latter is usually associated with complicated cataract extractions, ${ }^{24}$ and all cataract surgeries in this study were uncomplicated.

Moreover, it usually follows a benign course, ${ }^{25}$ and resolution of this component would be expected by 6 months of follow-up.

In diabetics with significant cataract, it is often difficult to visualise the retina adequately and retinal pathologies including macular oedema may easily be missed. Undetected CSMO at the time of surgery is less likely to resolve spontaneously as compared to CSMO arising de novo after surgery, and therefore expectant management would be inappropriate. Earlier treatment in the postoperative period using macular laser has been suggested. ${ }^{4}$ Injection of ivTA at the time of cataract extraction may therefore be a viable alternative. The surgeon may consider performing binocular indirect ophthalmoscopy (BIO) at the end of cataract extraction in such patients with significant cataract, and if CSMO (gross enough to be detected by BIO instead of the more conventional slit-lamp setting) is diagnosed intraoperatively, ivTA at the same operation setting may be an option.

Injection of ivTA has been associated with various potential complications, increase in IOP being the most common. In our study, four patients developed elevated IOP, which was transient in most and could be controlled with topical antiglaucomatous medications. Injection of ivTA may also be associated with risk of cataract progression. $^{26}$ The effect of severity of diabetes and glycaemic control could be other factors contributing to cataract progression, but these factors were not looked at in detail in the present study. Early cataract surgery in diabetic patients has previously been advocated, ${ }^{4}$ and by performing cataract extraction in combination with ivTA injection, this potential complication is no longer a consideration.

The most serious potential complication of ivTA injection is the development of endophthalmitis. None of our patients in this study developed this serious complication postoperatively. Moshfeghi et $a l^{27}$ reported several cases of endophthalmitis after ivTA injection. It was suggested that diabetes due to its association with immunosuppression, ${ }^{27,28}$ may be a risk factor for endophthalmitis after ivTA injections, and the authors recommended that in such patients consideration be given to delaying the procedure. However, diabetics with macular oedema make up a large proportion of patients who could potentially benefit from ivTA. It was also suggested that the risk for endophthalmitis may be increased in an office-based setting where the aseptic technique may not be as rigorous as in the operation theatre setting. In our series, all of our patients had diabetes mellitus and underwent the more invasive procedure of uncomplicated cataract extraction in addition to ivTA injection. Although our current series was limited in size, our study suggests that injection of ivTA is safe to perform in diabetic patients as long as there is strict adherence to aseptic technique including the use of a lid speculum and proper draping of the patient's eyelashes.

The true extent of the contribution of clearer media after cataract extraction in improving visual acuity of these patients with diabetic CSMO is difficult to ascertain, as we did not have a control group in our study comparing diabetic patients with CSMO who underwent phacoemulsification without ivTA. Nevertheless, anatomical improvement in macular oedema has previously been shown to be highly correlated with functional improvement in visual acuity in other studies using ivTA alone. ${ }^{14,17}$ Moreover, in this study, a dosage of $4 \mathrm{mg}$ of ivTA was used, and more significant effects may be seen with higher dosages.

In conclusion, preliminary data from this study indicate that diabetic patients with CSMO who undergo combined phacoemulsification and ivTA injection can have statistically significant improvement in BCVA that is maintained at 6 months postoperatively with no significant adverse events. To our knowledge, this is the first study in the literature documenting the safety and efficacy of combined phacoemulsification with ivTA injection as an alternative to conventional macular laser photocoagulation in diabetic patients diagnosed to have CSMO before cataract extraction. However, large-scaled randomised controlled trials are necessary for delineating the relative contributions of cataract removal and CMT reduction to visual acuity improvement. Moreover, our findings suggest that the effect of $4 \mathrm{mg}$ ivTA is transient, in concordance with other ivTA studies, and that the macular oedema is likely to recur. Further studies may be warranted to determine an optimal dose of ivTA, as well as the need and timing of subsequent ivTA injections. 


\section{References}

1 Gaudric A, Massin-Korobelnik P. Diabetic maculopathy: classification, epidemiology, spontaneous outcome, treatment. Diabetes Metab 1993; 19: 422-429.

2 Hamilton AMP, Ulbig MW, Polkinghorne P (eds). Epidemiology of diabetic retinopathy. In: Management of Diabetic Retinopathy. BMJ Publishing Group: London, 1996, pp 1-15.

3 Squirrell D, Bhola R, Bush J, Winder S, Talbot JF. A prospective, case controlled study of the natural history of diabetic retinopathy and maculopathy after uncomplicated phacoemulsification cataract surgery in patients with type 2 diabetes. Br J Ophthalmol 2002; 86: 565-571.

4 Dowler JG, Kulwant SS, Hykin PG, Hamilton PA. The natural history of macular edema after cataract surgery in diabetes. Ophthalmology 1999; 106: 663-668.

5 Dowler JF, Hykin PG, Hamilton PA. Phacoemulsification versus extracapsular cataract extraction in patients with diabetes. Ophthalmology 2000; 107: 457-462.

6 Antcliff RJ, Poulson A, Flanagan DW. Phacoemulsification in diabetics. Eye 1996; 10: 737-741.

7 The Royal College of Ophthalmologists. The Royal College of Ophthalmologists Published Guidelines: Cataract Surgery Guidelines 2001. http://www.rcophth.ac.uk/publications/ index.html

8 Bresnick GH. Diabetic maculopathy: a critical review highlighting diffuse macular edema. Ophthalmology 1983; 90: 1301-1317.

9 Scholes GN, O’Brien WJ, Abrams GW, Kubicek MF. Clearance of triamcinolone from vitreous. Arch Ophthalmol 1985; 103: 1567-1569.

10 Wilson CA, Berkowita BA, Sato Y, Ando N, Handa JT, de Juan Jr E. Treatment with intravitreal steroid reduces bloodretinal barrier breakdown due to retinal photocoagulation. Arch Ophthalmol 1992; 110: 1155-1159.

11 Antcliff RJ, Spalton DJ, Stanford MR, Graham EM, Ffytche TJ, Marshall J. Intravitreal triamcinolone for uveitic cystoid macular edema: an optical coherence tomography study. Ophthalmology 2001; 108: 765-772.

12 Stern AL, Tylor DM, Dalburg LA, Cosentino RT. Pseudophakic cystoid maculopathy: a study of 50 cases. Ophthalmology 1981; 88: 942-946.

13 Suckling RD, Maslin KF. Pseudophakic cystoid macular oedema and its treatment with local steroids. Aust NZ J Ophthalmol 1998; 16: 353-359.

14 Jonas JB, Kreissig I, Sofker A, Degenring RF. Intravitreal injection of triamcinolone for diffuse diabetic macular edema. Arch Ophthalmol 2003; 121: 57-61.
15 Early Treatment Diabetic Retinopathy Study Research Group. Early photocoagulation for diabetic retinopathy. ETDRS report number 9. Ophthalmology 1991; 98: 766-785.

16 Lee CM, Olk RJ. Modified grid laser photocoagulation for diffuse diabetic macular edema. Long-term visual results. Ophthalmology 1991; 98: 1594-1602.

17 Martidis A, Duker JS, Greenberg PB, Rogers AH, Puliafito $\mathrm{CA}$, Reichel $\mathrm{E}$ et al. Intravitreal triamcinolone for refractory diabetic macular edema. Ophthalmology 2002; 109: 920-927.

18 Wingate RJ, Beaumont PE. Intravitreal triamcinolone and elevated intraocular pressure. Aust NZ J Ophthalmol 1999; 27: 431-432.

19 Jonas JB, Kreissig I, Degenring R. Intraocular pressure after intravitreal injection of triamcinolone acetonide. $\mathrm{Br} J$ Ophthalmol 2003; 87: 24-27.

20 Bakri SJ, Beer PM. The effect of intravitreal triamcinolone acetonide on intraocular pressure. Ophthalmic Surg Lasers Imaging 2003; 34: 386-390.

21 Sutter FK, Gillies MC. Pseudo-endophthalmitis after intravitreal injection of triamcinolone. Br J Ophthalmol 2003; 87: 972-974.

22 Roth DB, Chieh J, Spirn MJ, Green SN, Yarian DL, Chaudhry NA. Noninfectious endophthalmitis associated with intravitreal triamcinolone injection. Arch Ophthalmol 2003; 121: $1279-1282$.

23 Benz MS, Murray TG, Dubovy SR, Katz RS, Eifrig CW. Endophthalmitis caused by Mycobacterium chelonae abscesses after intravitreal injection of triamcinolone. Arch Ophthalmol 2003; 121: 271-273.

24 Ray S, D’Amico DJ. Pseudophakic cystoid macular edema. Semin Ophthalmol 2002; 17: 167-180.

25 Pollack A, Leiba H, Bukelman A, Oliver M. Cystoid macular oedema following cataract extraction in patients with diabetes. Br J Ophthalmol 1992; 76: 221-224.

26 Gillies MC, Simpson JM, Luo W, Penfold P, Hunyor AB, Chua $\mathrm{W}$ et al. A randomized clinical trial of a single dose of intravitreal triamcinolone acetonide for neovascular age-related macular degeneration: one-year results. Arch Ophthalmol 2003; 121: 667-673.

27 Moshfeghi DM, Kaiser PK, Scott IU, Sears J, Benz M, Sinesterra JP et al. Acute endophthalmitis following intravitreal triamcinolone acetonide injection. $A m \mathrm{~J}$ Ophthalmol 2003; 136: 791-796.

28 Phillips II WB, Tasman WS. Postoperative endophthalmitis in association with diabetes mellitus. Ophthalmology 1994; 101: 508-518. 